(2) Open Access Full Text Article

CASE REPORT

\title{
Woman presenting with chronic iron deficiency anemia associated with hereditary hemorrhagic telangiectasia: a case report
}

This article was published in the following Dove Press journal:

Drug, Healthcare and Patient Safety

15 November 2013

Number of times this article has been viewed

\section{Paul Stross \\ Department of Haematology, St Richard's Hospital, Chichester, United Kingdom}

Correspondence: Paul Stross Department of Haematology, St Richard's Hospital, Spitalfield Lane, Chichester POI 9 6SE, United Kingdom Tel +44 I243 83I 65I

Fax +44 I243 83I 4I3

Email paul.stross@wsht.nhs.uk
Background: Hereditary hemorrhagic telangiectasia is an autosomal dominant disorder associated with frequent nose bleeds that can be troublesome and difficult to contain. A further manifestation is telangiectasia, which may develop in the upper and lower gastrointestinal tract. The associated blood loss can be chronic, resulting in iron deficiency anemia which, when severe, has historically been treated by blood transfusions. Further pulmonary, neurologic, and hepatic complications may appear in later life, and are well documented. Administering blood transfusions requires provision, storage, and serological testing to select suitable units. Recognition of the inherent potential risks of donated blood, the expense, and the concerns regarding blood supply, has resulted in a national policy for conservation and appropriate use of blood. For an individual patient, there may be development of alloantibodies which complicates future cross-matching for transfusions.

Case report: SG is a 66-year-old Caucasian woman who first presented to our hematology department in 2003, having just moved to the area. She had suffered with nose bleeds since her teenage years and presented with a low hemoglobin level and symptoms of iron deficiency anemia. Medical and nonmedical interventions failed to arrest the blood loss, which had not been massive or associated with hypovolemic shock. Pursuant to conserving blood supplies, and based on experience of patients with other causes of iron deficiency anemia, a regimen of high-dose iron supplementation was adopted. The aim was to sustain iron stores as a substrate for erythropoiesis and thereby achieve adequate hemoglobin levels whilst minimizing the need for blood transfusion.

Discussion: This approach has maintained the patient's hemoglobin levels at $6.4-11.6 \mathrm{~g} / \mathrm{dL}$ over a period of 9 years. Until the time of writing in 2011, the maximum number of blood transfusions she has received in a year has been six, albeit there has been a steady slow increase since 2006. Her quality of life has been good throughout, with good levels of activity, a normal lifestyle, and no pain. The high-dose iron regimen is estimated to have avoided administration of up to 90 units of blood in 2011, at a saving to the National Health Service of at least $£ 7000$.

Keywords: iron deficiency anemia, hereditary hemorrhagic telangiectasia, epistaxis, intravenous iron, low molecular weight iron dextran

\section{Introduction}

Hereditary hemorrhagic telangiectasia (HHT), also known as Osler-Weber-Rendu disease, is a relatively rare genetic condition associated with epistaxis due to capillary telangiectasias. ${ }^{1,2}$ The prevalence of the condition in the UK has been reported to be approximately one in 40,000, with equal distribution between men and women., However, the prevalence may vary with ethnicity and geographic location., 
Several genes are implicated in this autosomal-dominant condition (eg, ENG, ACVRL1 [ALK1] and SMAD4). HHT type 1 (HHT1) is associated with $E N G$ and HHT2 is associated with $A C V R L 1$. These genes are involved in vascular development and repair. Mutations in HHT1 are associated with a higher frequency of pulmonary arteriovenous malformation, whereas mutations in HHT2 appear to be associated with hepatic lesions. ${ }^{3,5}$ Other loci (ie, HHT3 and HHT4) appear to have mutations in two as yet unknown genes. ${ }^{5}$

The condition is associated primarily with frequent nose bleeds by the age of 16 years in over half of diagnosed patients. Over $90 \%$ of patients with HHT experience frequent nose bleeds by the age of 30 years. ${ }^{2}$ These nose bleeds rarely cause problems during childhood, albeit the initial signs that a child has HHT may be nose bleeds that are heavier and more frequent than those in other children. In adults, uncontrolled epistaxis may cause or contribute to iron deficiency anemia (IDA). Treatment options include antifibrinolytics, estrogen or progesterone therapy, laser therapy, surgery, and embolization. $^{3}$

In HHT, telangiectasias may also be found on the face, lips, tongue, oral mucosa, gums, conjunctiva, trunk, arms, and fingertips. Blood loss from these sites is normally mild and often readily controlled with laser ablation. ${ }^{3}$

Gastrointestinal telangiectasias may be found in the stomach and the large and small intestines. These can be significant in $15 \%-30 \%$ of patients, and are associated with acute or chronic bleeding. This blood loss rarely occurs prior to the age of 30 years, but if uncontrolled can lead to IDA. Treatment options include estrogen and progesterone therapy, antifibrinolytic agents, and laser therapy to reduce the severity of blood loss. The need for blood transfusions to address IDA reflects the severity and persistence of blood loss. ${ }^{3}$

A further manifestation of HHT is arteriovenous malformation. The prevalence of pulmonary arteriovenous malformation is $5 \%-30 \%$ in HHT patients over the age of 30 years. Patients may be symptom-free or present with massive bleeding or hemoptysis caused by thoracic hemorrhage. Patients may also present with symptoms of hypoxemia or orthodeoxia, with dyspnea, cyanosis, clubbing, and polycythemia related to right-to-left shunting. Brain abscess and stroke, secondary to thrombi bypassing the lungs, are potentially serious sequelae. These patients require appropriate and timely investigation. Embolization is the preferred treatment or, if inappropriate, surgery, with screening to detect growth or recanalization of identified and treated malformations and the appearance of new lesions. ${ }^{3}$
Hepatic arteriovenous malformations may occur in up to $70 \%$ of patients with HHT. The majority of these are "silent", but may provoke congestive heart failure, portal hypertension and, rarely, liver failure, with or without encephalopathy. Neurologic issues can occur in $10 \%-15 \%$ of patients with HHT. Occurring later in life, these may result in transient ischemic attack, ischemic stroke, and brain abscess related to pulmonary arteriovenous malformations with right-to-left shunting. Cerebral and spinal arteriovenous malformations can provoke severe and devastating hemorrhage. ${ }^{3}$

However, the focus of this case history is anemia associated with HHT. A history of hematemesis or melena may be anticipated in $33 \%$ of patients with HHT. ${ }^{6}$ Of these, approximately half will require blood transfusion as part of supportive care. In a well-defined total HHT population in Denmark, $9 \%$ received at least 6 units of blood in a 6-month period and were classified as having severe bleeding. ${ }^{6}$ Telangiectatic lesions were observed in all patients. Endoscopy confirmed telangiectasias in a similar cohort of patients with HHT in the US and severe bleeding (defined as $\geq 12$ units of packed cells transfused per year or a mean hemoglobin level $\leq 80 \mathrm{~g} / \mathrm{L}) .{ }^{7}$ Endoscopy identified lesions in the esophagus, stomach, duodenum, jejunum, and colon. Patients with more than 20 telangiectasias visualized by esophagogastroduodenoscopy had a significantly lower mean hemoglobin level compared with those with fewer than 20 lesions $(7.9 \mathrm{~g} / \mathrm{dL}$ versus $9.4 \mathrm{~g} / \mathrm{dL}, P=0.007)$, with a trend toward higher blood transfusion requirements. ${ }^{7}$ Permanent cure of gastrointestinal bleeding is seldom feasible in transfusion-dependent patients, with optimal management including both medical and endoscopic approaches.

Anemia associated with severe bleeding has traditionally resulted in patients receiving frequent blood transfusions, although Grand'Maison urged that “... infusions of iron must be received on a regular basis to reduce the need for transfusion". ${ }^{3}$

In 2002, a health service circular (HSC, 2002/009) established the foundations for safer and appropriate administration of blood in the UK (seeking to avoid the unnecessary use of blood and blood components). ${ }^{8}$ This was subsequently updated and reinforced by HSC 2007/001. ${ }^{9}$ These documents from the Department of Health sought to encourage alternatives to blood transfusions, thereby preserving stocks for patients who are reliant on blood or require blood acutely. Through such action, patient exposure to blood per se as well as the process of matching and infusing is reduced.

For patients with chronic IDA, iron supplementation with or without concomitant erythropoiesis-stimulating therapy may 
offer an alternative to blood transfusion. In the presence of endogenous erythropoietin, iron supplementation alone has been demonstrated to establish functional iron adequacy and provoke erythropoiesis to sustain target hemoglobin levels across a spectrum of conditions that cause IDA. ${ }^{10-15}$

Whilst oral iron supplements are less costly than intravenous formulations, their performance is inferior because of physiological barriers to oral iron absorption. ${ }^{14-16}$ This is particularly emphasized in clinical situations where there is chronic blood loss, and absorption of oral iron is unable to keep pace with the iron lost through bleeding. In addition to the pharmacokinetic shortfall of oral iron, high levels of adverse gastrointestinal symptoms cause poor tolerance and poor compliance, which further detracts from its use. ${ }^{16,17}$

This case report reviews the treatment of a woman with chronic severe blood loss associated with HHT, who has been successfully managed with high-dose intravenous iron over a period of years without concomitant erythropoiesisstimulating therapy.

\section{Case report}

$\mathrm{SG}$ is a Caucasian housewife, born in 1946, who was diagnosed with HHT in her teens. Her father and paternal grandmother also had HTT, mostly with epistaxis. Her father suffered badly with nose bleeds and some stomach bleeding, but his brother did not have HHT. Her daughter is untested, but has no symptoms.

SG recalls "... always having telangiectasia on my tongue" and on her hand, but these were not problematic and did not require treatment (Figures 1 and 2). Apart from symptoms associated with HHT, SG has had no significant comorbidities. Symptoms of HHT that have been problematic include nose bleeds since her late teens and gastrointestinal

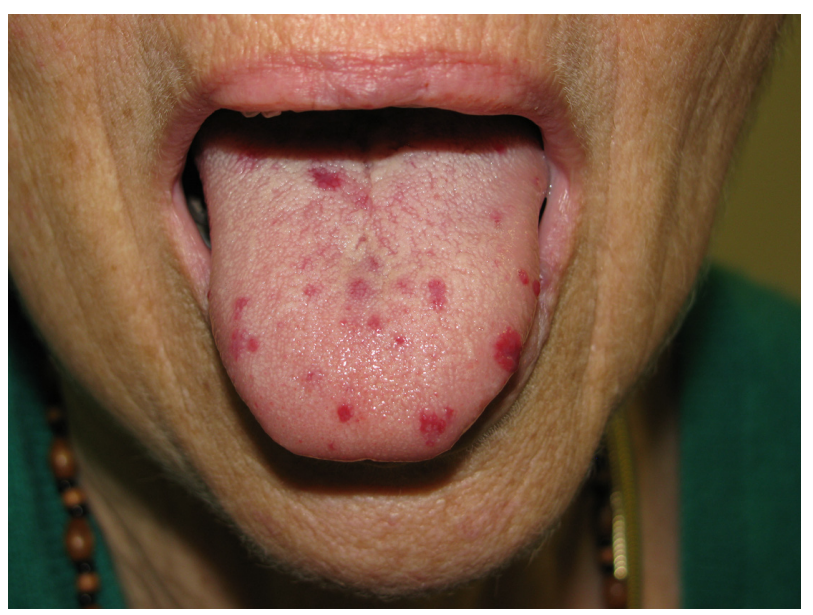

Figure I The easily visible multiple telangiectasias found over the tongue. These are useful for making a clinical diagnosis.

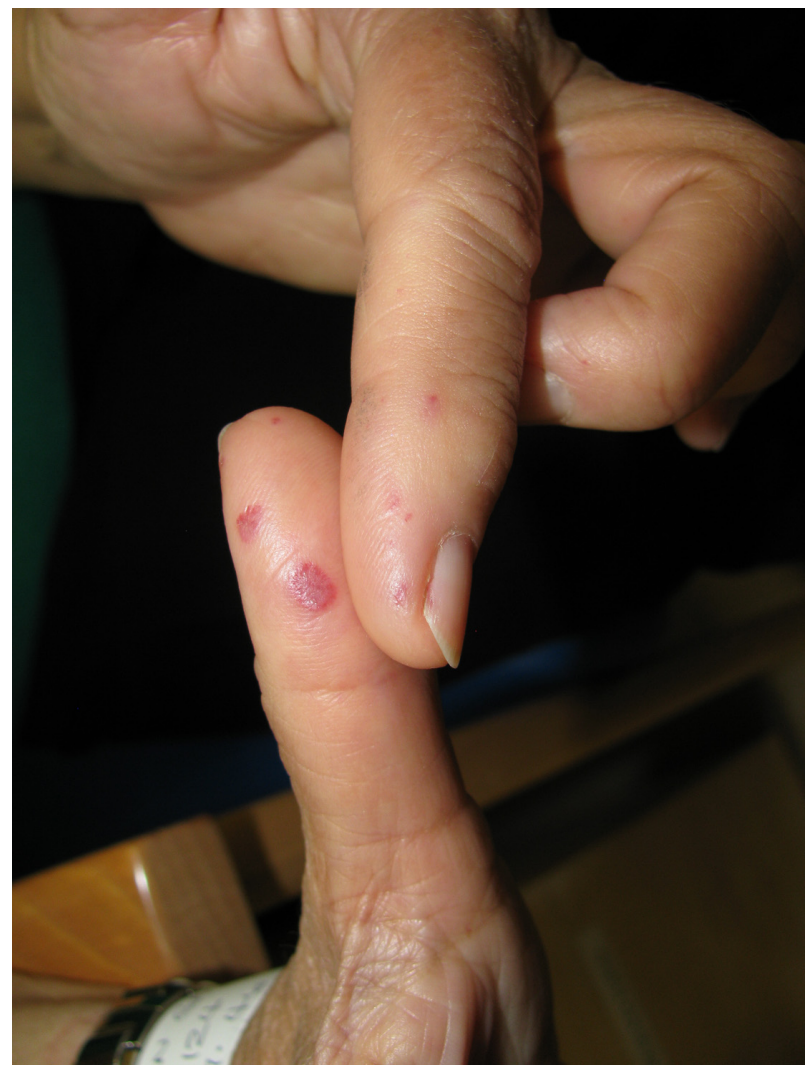

Figure 2 Multiple digital telangiectasias.

bleeds (including from the small bowel) that led to her symptoms and a diagnosis of anemia. Occult fecal blood loss and abnormal hematologic parameters were observed when she was first referred to our unit in 2003. Her genotype is unknown.

In the last 10 years, a variety of investigations has been undertaken at a number of secondary and tertiary units. These were to monitor the progress of her condition and intervene appropriately to control blood loss. Enteroscopy (see Table 1) was preceded by capsule endoscopy to locate and quantify telangiectasias and to provide information on blood loss, in particular, the color of luminal fluid.

Table I Key visceral interventions

\begin{tabular}{|c|c|c|}
\hline Date & Investigation & Result \\
\hline $\begin{array}{l}\text { March } \\
2006\end{array}$ & $\begin{array}{l}\text { Double balloon } \\
\text { enteroscopy }\end{array}$ & $\begin{array}{l}\text { Multiple proximal small bowel } \\
\text { angiodysplasias identified and ablated } \\
\text { and several large gastric lesions }\end{array}$ \\
\hline $\begin{array}{l}\text { September } \\
2006\end{array}$ & $\begin{array}{l}\text { Double balloon } \\
\text { enteroscopy }\end{array}$ & $\begin{array}{l}\text { Multiple angioectasias ablated in } \\
\text { distal duodenum and proximal } \\
\text { jejunum plus additional lesions in } \\
\text { distal jejunum and proximal ileum }\end{array}$ \\
\hline $\begin{array}{l}\text { November } \\
2008\end{array}$ & $\begin{array}{l}\text { Spirus Discovery SB } \\
\text { enteroscopy - argon } \\
\text { plasma coagulation }\end{array}$ & $\begin{array}{l}\text { 30-35 small bowel angioectasias } \\
\text { ablated plus solitary gastric } \\
\text { angioectasia }\end{array}$ \\
\hline
\end{tabular}


Efforts to eliminate or reduce the amount of blood loss due to gastrointestinal angiodysplasia have met with limited success. The patient has undergone periodic argon beam coagulation therapy (every 8 weeks) for bleeding stomach lesions and occasional laser therapy for small intestinal lesions.

Nose bleeds are a frequent but unpredictable manifestation of HHT and have been troublesome for SG. Key interventions took place in 2005 and 2007 (see Table 2). Laser treatment has had only limited success in preventing her nose bleeds. A skin transplant was suggested as a further potential intervention, but she has declined to pursue this option.

Cognizant of the possible development of pulmonary arteriovenous malformation, we screened the patient for this condition in 2009. She had no respiratory or neurologic symptoms, eg, transient ischemic attacks or unexplained neurologic events, attributable to pulmonary arteriovenous malformation. Oxygen saturation levels were $96 \%$ (erect) and $93 \%$ (supine) in the setting of normal/obstructed spirometry by flow volume loop. The chest x-ray was clear and computed tomography using a dedicated protocol identified no pulmonary arteriovenous malformations. Cerebral magnetic resonance imaging was undertaken in 2004 , despite the patient having no symptoms or relevant family history. No evidence of cerebral angioectasias was found. Computed tomography in 2009 identified telangiectasias in the liver, but liver function tests were normal. Because her telangiectasias were not severe, treatment has not been initiated.

Early attempts to stem the loss of blood involved administration of the antifibrinolytic agent, tranexamic acid. No discernible benefit has been observed, but SG continues to receive this medication. A trial of thalidomide was undertaken in 2008 for a period of 2 months, but again this seemed to be of little benefit. There was no improvement in her hemoglobin level and she found the drug difficult to tolerate because of side effects, so the drug was stopped.

Newer antiangiogenesis therapies have been considered, but with equivocal evidence of benefit and a relatively high risk of potential side effects, so these options have not been pursued. Likewise, tamoxifen was considered, but this would have required ultrasound monitoring of the uterus for potential endothelial hyperplasia (SG has not had a hysterectomy), and

Table 2 Key interventions for epistaxis

\begin{tabular}{ll}
\hline Date & Treatment \\
\hline March 2005 & KTP (potassium-titanyl-phosphate) laser on nose \\
June 2005 & KTP laser on nose \\
August 2007 & KTP laser on nose \\
\hline
\end{tabular}

because it is thrombogenic, it was considered inappropriate for her to be receiving tamoxifen as well as tranexamic acid. These interventions have complemented other forms of nonmedical therapy being used in an attempt to curtail chronic blood loss.

Whilst the management of HHT in this patient has involved prevention of blood loss, she has continued to bleed, so a number of strategies have been undertaken to replace the lost blood. Initially, oral ferrous sulfate supplementation was administered in an attempt to contain her anemia. This was both unsuccessful and very poorly tolerated.

In October 2003, a regimen of high-dose intravenous iron infusions was commenced, seeking to replace and sustain iron stores to allow natural erythropoiesis to keep pace with the chronic blood loss. This approach was successful both in sustaining acceptable hemoglobin levels (albeit below the $12.5 \mathrm{~g}$ / dL level recommended by the World Health Organization for women) but generally avoiding symptoms of anemia and the need for high-frequency and high-volume blood transfusions, but SG still required an occasional blood transfusion.

Whilst this approach was successful for 7 years, a "step-up" in transfusion requirements was necessary in 2011 (Table 3), even though ferritin levels were rendered high (Table 4). In April 2010, a bone marrow aspirate confirmed that there was no cause of anemia other than that resulting from blood loss.

Since 2003, SG has received in excess of 99 infusions of low molecular weight iron dextran $\left(\right.$ Cosmofer $^{\circledR}$, Pharmacosmos UK Ltd, Oxford, UK). The dose of iron administered has been modulated, endeavoring to maintain iron stores adequate to sustain erythropoiesis and to keep pace with blood loss. This has been complemented with blood transfusions when needed. SG has received 36 blood transfusions (91 units of blood) since commencing high-dose iron infusions in 2003. The number of transfusions and units of blood given has gradually increased over 8 years to 10 infusions ( 25 units of blood) in 9 months during 2011.

Table 3 Blood transfusions each year and units of blood received

\begin{tabular}{lll}
\hline Year & $\begin{array}{l}\text { Number } \\
\text { of transfusions }\end{array}$ & $\begin{array}{l}\text { Units of blood } \\
\text { received }\end{array}$ \\
\hline 2003 & 1 & 3 units \\
2004 & 1 & 2 units \\
2005 & 0 & 0 units \\
2006 & 4 & 9 units \\
2007 & 3 & 7 units \\
2008 & 5 & 13 units \\
2009 & 6 & 15 units \\
2010 & 6 & 17 units \\
2011 (to end Sept) & 10 & 25 units \\
Total & 36 & 91 units \\
\hline
\end{tabular}


Table 4 Maximum and minimum annual Hemoglobin $(\mathrm{Hb})$, ferritin and reticulocyte levels

\begin{tabular}{lllllll}
\hline Year & $\begin{array}{l}\text { Minimum } \\
\text { Hb level } \\
\text { in year g/dL }\end{array}$ & $\begin{array}{l}\text { Maximum } \\
\text { Hb level } \\
\text { in year g/dL }\end{array}$ & $\begin{array}{l}\text { Minimum } \\
\text { ferritin level } \\
\text { in year } \mu \text { g/dL }\end{array}$ & $\begin{array}{l}\text { Maximum } \\
\text { ferritin level } \\
\text { in year } \mu \mathbf{g} / \mathbf{d L}\end{array}$ & $\begin{array}{l}\text { Minimum } \\
\text { reticulocyte level } \\
\text { in year 10\%/L }\end{array}$ & $\begin{array}{l}\text { Maximum } \\
\text { reticulocyte level } \\
\text { in year I0\%/L }\end{array}$ \\
\hline 2003 & 7.0 & 10.5 & $42^{*}$ & $42^{*}$ & $219^{*}$ & $219^{*}$ \\
2004 & 8.4 & 11.2 & 19 & 258 & 119 & 190 \\
2005 & 6.8 & 10.0 & 237 & 515 & 152 & 225 \\
2006 & 7.1 & 11.1 & 376 & 1182 & 98 & 213 \\
2007 & 6.4 & 11.6 & 617 & 978 & 124 & 280 \\
2008 & 7.4 & 10.4 & 411 & 686 & 139 & 290 \\
2009 & 6.8 & 10.5 & 165 & 482 & 213 & 269 \\
2010 & 6.9 & 9.8 & 132 & 537 & 241 & 246 \\
2011 (to end Sept) & 7.0 & 9.3 & 128 & 502 & 262 & 332 \\
\hline
\end{tabular}

Note: *Only a single record for 2003.

The procedure for administering low molecular weight iron dextran infusions incorporates a test dose followed by the balance of the iron dose. The full iron dose is diluted in $500 \mathrm{~mL}$ of saline to complete the infusion in 5 hours. ${ }^{18}$ This is undertaken in the hematology day unit at the hospital. The dose has been varied in an attempt to keep pace with blood loss as the disease has progressed. The initial approach was to meet demand by increasing the amount of iron incrementally per infusion to a maximum of $2000 \mathrm{mg}$ per infusion, based on $20 \mathrm{mg} / \mathrm{kg}$ body weight. ${ }^{18}$ Because the patient has now lost weight, the amount per infusion has been reduced, with the maximum amount of iron per infusion being $1500 \mathrm{mg}$, and the frequency of infusions has been increased. Currently, SG receives one infusion every 3 weeks. In 2004, SG received $14.1 \mathrm{~g}$ of elemental iron. In 2010 , the total amount was $14.5 \mathrm{~g}$ and in the first 9 months of 2011 was $15 \mathrm{~g}$.

Only a single reaction to iron infusion has occurred. This was at the time of the first administration. The reaction was minor and occurred during the test dose period after about 5 minutes. The reaction was described as "uncomfortable flushing" of the face, but there were no cardiovascular manifestations (eg, hypotension), dyspnea, or symptoms suggestive of an allergic reaction. As a precaution, hydrocortisone $100 \mathrm{mg}$ and chlorpheniramine $10 \mathrm{mg}$ were administered intravenously along with $1000 \mathrm{mg}$ of oral paracetamol. She has received a further 98 infusions at the time of writing.

As her condition has progressed, SG has accommodated to fatigue and tiredness, which is particularly noticeable when her hemoglobin level falls to $6-7 \mathrm{~g} / \mathrm{dL}$, ie, well below the lower limit of normal. She manages walks to the shops (one mile each way) on most days and enjoys walks which do not involve hills. Her social and family lifestyle and activities have not been impaired. There is no evidence of withdrawal, depression, anxiety, or abnormal emotional functioning. She has no pain attributable to her condition.
SG and her husband are retired, so particular emphasis is placed on planning and taking holidays together, especially overseas, and these involve long flight times. Ahead of these vacations, particular attention is paid to achieving good iron stores and hemoglobin levels at the upper end of her achievable hemoglobin spectrum, so that she can avoid unplanned hospital visits whilst away and optimize her energy and activity. This "pre-emptive" approach has been particularly appreciated. The most difficult symptoms that impact her lifestyle are nose bleeds, that can occur at any time, be prolonged, and difficult to halt.

\section{Discussion}

The strategy for clinical management of SG includes:

- Prevention of blood loss.

- Treatment to correct anemia associated with blood loss.

- Vigilance and investigation, with age-appropriate screening for potential complications.

The pattern of her HHT is following a familiar pattern, and is increasing in severity with age. The signs of telangiectasia on her tongue and thumb cause little discomfort or clinical concern (Figures 1 and 2). However, the nose bleeds have become more significant and increasingly troublesome, averaging two a week and taking a minimum of 20 minutes to resolve, despite ongoing use of tranexamic acid since 2003 and bouts of potassium titanyl phosphate laser treatment.

Thalidomide has been prescribed, as a result of it having been demonstrated to reduce the severity and frequency of nose bleeds in patients with HHT by a mechanism that enhances blood vessel stabilization. ${ }^{19}$ It has also been associated with blood vessel maturation which may be useful in reducing arteriovenous malformations related to gastrointestinal bleeding. ${ }^{19}$ An 8-week trial of thalidomide in 2008 did not influence her hemoglobin levels, and she experienced side effects, so this treatment was discontinued. 
Epistaxis is a known contributor to IDA, and its resolution can be critical in reducing the severity and chronicity of IDA. ${ }^{3}$ In addition to epistaxis, SG suffers from gastrointestinal bleeding, in particular from the small bowel. These bleeds have been investigated, located, and treated using a variety of procedures, often on referral to tertiary specialist units. Double-balloon enteroscopy, also known as "push-pull enteroscopy" or the "double-bubble", is an endoscopic technique that allows complete examination of the small bowel with ablation of angiodysplasia. Double-balloon enteroscopy is a technique complementary to small bowel capsule endoscopy, which has also been repeatedly undertaken in this patient. Double-balloon and capsule endoscopy in combination are two of the most powerful, noninvasive, and easy methods for investigating the small bowel. Subsequently, the more recently introduced spiral enteroscopic technique was undertaken in this patient in 2008.

Stomach lesions identified on investigation were treated with periodic argon beam coagulation. Small intestine lesions have been treated with laser therapy. Unfortunately, despite these many interventions, the impression is that her hemoglobin has not responded positively in the short term.

Despite treatment of mucosal telangiectasias and epistaxis, there has been only partial success in reducing her progressively increasing blood loss, and her ferritin level tends to fall if vigorous supplementation with intravenous iron is not maintained.

The focus of this case report is on addressing the IDA associated with the patient's ongoing blood loss. SG is regarded as having high blood loss (requiring in excess of 12 units of blood per year). Traditionally, blood transfusions are used to manage blood loss, but are not without risk and can trigger production of antibodies, which may increase the difficulty of cross-matching for future blood transfusions. Fortunately, cross-matching problems have not evolved in this patient.

Blood conservation policies apply throughout the National Health Service, and all encourage the use of "alternatives" to blood. In this context, a treatment regimen embracing highdose intravenous iron supplementation has been adopted to manage the IDA associated with chronic blood loss.

Since 2003, SG has received high-dose intravenous iron (low molecular weight iron dextran) as the backbone of her IDA treatment. In 2011, this was still the mainstay of her therapy, although progression of her disease has resulted in a growing demand for additional blood transfusions when symptoms of anemia become apparent.

The decision for hematologic intervention is based on routine hemoglobin, ferritin, and reticulocyte monitoring as well as her symptoms of anemia. Further tests are undertaken from time to time to support decision-making. Her mean corpuscular volume is often high (104 fL), with serum iron fluctuating at low levels $(6.7-6.9 \mu \mathrm{mol} / \mathrm{L})$, high erythropoietin levels (200 IU/L), globulin levels fluctuating at low levels (around $19 \mathrm{~g} / \mathrm{L}$ ), and low immunoglobulin G levels (about $3.8 \mathrm{~g} / \mathrm{L}$ ), which probably reflect blood loss. We have not yet quantified her blood loss with isotope ferrokinetic studies. Angiography has not been performed.

In anticipation of future blood loss, the aim of intravenous iron treatment is to maintain her iron stores in the range of $50-500 \mu \mathrm{g} / \mathrm{dL}$ to sustain endogenous erythropoiesis and avoid her hemoglobin level falling below $7 \mathrm{~g} / \mathrm{dL}$, thereby avoiding a crisis. This "anticipatory" approach cannot be undertaken using blood, because hemoglobin values may rise to unsafe levels.

Over an 8-year period, this approach has sustained her hemoglobin levels between $6.4 \mathrm{~g} / \mathrm{dL}$ and $11.6 \mathrm{~g} / \mathrm{dL}$. The World Health Organization defines anemia in women as a hemoglobin level below $12.0 \mathrm{~g} / \mathrm{dL} .{ }^{20}$ Our hematology laboratory suggests a minimum normal level of $11.5 \mathrm{~g} / \mathrm{dL}$. For much of the time, SG has experienced hemoglobin levels below this level, but has avoided extremely low levels that would have profoundly detracted from her quality of life and lifestyle.

Her ferritin levels have been sustained in the range of $19-1182 \mu \mathrm{g} / \mathrm{dL}$. The World Health Organization indicates that iron deficiency is a level below $15 \mu \mathrm{g} / \mathrm{dL}{ }^{21}$ The lower and upper limits of normal for ferritin at our laboratory are currently $11 \mu \mathrm{g} / \mathrm{dL}$ and $307 \mu \mathrm{g} / \mathrm{dL}$, respectively. SG was continuously above the minimum and has mostly had ferritin levels above the threshold for IDA during the years 2005-2011. Her maximum ferritin levels have frequently been above the laboratory maximum of $307 \mu \mathrm{g} / \mathrm{dL}$. Such levels are common in patients with chronic kidney disease receiving intravenous iron supplementation, and whilst the debate continues regarding the maximum tolerable level, the revised renal guidelines from the National Institute for Health and Clinical Excellence in 2011 suggest sustaining ferritin levels within a range of $200-500 \mu \mathrm{g} / \mathrm{dL} .{ }^{22}$ Besarab et al suggest that efficacy is optimal using erythropoiesis-stimulating agents with ferritin levels at 500-800 (mean 600) $\mu \mathrm{g} / \mathrm{dL}{ }^{23}$ There is little evidence for suggesting a specific upper limit. There has been no evidence of adverse effects as a result of high ferritin levels in SG, with high levels tending to fall spontaneously.

Reticulocyte monitoring has revealed levels continuously above the upper limit of normal. This reticulocytosis, 
indicative of bone marrow activity as a response to blood loss and ensuing anemia, has progressively increased as the patient's disease has progressed, especially during the latter years, although many patients with hemolytic anemias sustain higher values.

In addition to the immediate clinical justification for using intravenous iron, other advantages of intravenous iron over blood transfusion include:

- A reduced exposure to inherent risk of blood products (eg, prions).

- A reduced risk associated with blood transfusion procedure.

- A reduced risk of antibody production that affects future cross-matching for blood transfusions/transplant if needed.

- Cost benefits.

- Easier achievement of a normal "physiologic" hemoglobin level for individual patients.

- Speed and reliability in replacement of iron stores.

- Rapid high-dose, high-repletion possibilities.

- Clinical convenience, in that intravenous iron does not require refrigeration and has a long shelf-life with no compatibility issues.

In addition to the clinical benefits of using intravenous iron, the economic benefits are also important, in view of the current austere environment of the National Health Service.

The cost of a unit of blood containing approximately $250 \mathrm{mg}$ of iron is $£ 125.00$ in the UK. ${ }^{24,25}$ Based on our patient's iron requirements in 2011, the annual cost of her iron infusions is estimated at $£ 1793.25$. This compares favorably with the blood transfusions required to deliver a similar level of iron replenishment, ie, 90 units of blood costing $£ 9456.75$, which represents a saving of $£ 7663.50$. Further, the cost of cross-matching is saved, and whereas intravenous iron is administered over 5 hours, an equivalent blood transfusion (6 units) would be administered over 9-12 hours, accruing further savings to the National Health Service for bed use and overnight stays. ${ }^{25}$

SG has had only one reaction to low molecular weight iron dextran infusion, which was not associated with an allergic response. This type of response, with symptoms but no change in vital signs or evidence of shock, quickly disappears without treatment, and does not occur with rechallenge. It was first described by Fishbane, and is commonly referred to as the "Fishbane reaction". ${ }^{26}$ Since this early reaction, all further infusions have been administered uneventfully.
SG continues to lose whole blood. Her regular endoscopic assessments usually find bleeding lesions in the stomach. Recently, her hemoglobin levels have often been suboptimal despite normal vitamin B12 and folate levels and keeping her ferritin high. The causes may be multifactorial and include:

- A tendency for HHT to deteriorate with age.

- The erythroid response potentially being blunted by a deficiency of depleted factor(s), other than iron, and which have not been adequately replaced.

- Bone marrow may utilize intravenous iron less readily than, eg, iron released in hemolytic breakdown of red cells.

Nevertheless, intravenous iron infusions have been the backbone of anemia therapy for SG over the years and enabled her to maintain a good quality of life.

\section{Conclusion}

HHT has followed a progressive path in the patient described here, which is predictable from the literature. The potential for hepatic, neurologic, and pulmonary complications with age has been recognized and investigated, and except for minor nonsymptomatic hepatic involvement, there has been no evidence of arteriovenous malformation. Blood loss from gastrointestinal telangiectasias and nose bleeds is ongoing, and interventions appear to have been unsuccessful.

Notwithstanding various medical and surgical procedures, our patient has continued to have high blood loss that has been detrimental to her hemoglobin levels, with potential adverse implications for her quality of life. This has been avoided by aggressive repletion of her iron stores and addressing IDA with frequent high doses of low molecular weight iron dextran. Such an approach has exploited the normal physiological erythropoietin pathway to maintain normal hemoglobin levels, with a "top-up" transfusion when she is symptomatic.

This case report provides evidence that intravenous iron can play a major role in managing IDA. It further indicates that low molecular weight iron dextran is safe, even when used in repeated high doses, and has highlighted the importance of recognizing the so-called Fishbane response which, to the clinician inexperienced in using intravenous iron, could deter use. If this had occurred in SG, the likelihood is that blood use would have been considerably higher, adding considerable burden to the demand for blood, the associated risks of yearly multiple blood transfusions, and considerable additional expenditure to the National Health Service. 
In addition to demonstrating the clinical role that intravenous iron can play in the management of IDA associated with HHT, this case report shows that IDA can be managed more economically using intravenous iron than using blood transfusions alone, saving the National Health Service over $£ 7000$ in 2011.

\section{Acknowledgments}

We acknowledge Pharmacosmos UK Ltd, and Stewart Stanley for assisting with the preparation of the manuscript.

\section{Disclosure}

The author reports no conflicts of interest in this work.

\section{References}

1. Guttmacher AE, Marchuk DA, White RI. Hereditary hemorrhagic telangiectasia. N Engl J Med. 1995;333:918-924.

2. Porteus ME, Burn J, Procter SJ. Hereditary hemorrhagic telangiectasia: a clinical analysis. J Med Genet. 1992;29:527-530.

3. Grand'Maison A. Hereditary hemorrhagic telangiectasia. Can Med Assoc J. 2009;180:833-835.

4. Westermann CJ, Rosina AF, De Vries V, de Coteau PA. The prevalence and manifestations of hereditary hemorrhagic telangiectasia in the AfroCaribbean population of The Netherlands Antilles: a family screening. Am J Med Genet A. 2003;116A:324-328.

5. McDonald J, Pyeritz RE. Hereditary hemorrhagic telangiectasia. GeneReviews. Available from: http://www.ncbi.nlm.nih.gov/books/ NBK1351/. Accessed November 8, 2011.

6. Kjeldsen AD, Kjeldsen J. Gastrointestinal bleeding in patients with hereditary hemorrhagic telangiectasia. Am J Gastroenterol. 2000;95: 415-418.

7. Longacre AV, Gross CP, Gallitelli M, et al. Diagnosis and management of gastrointestinal bleeding in patients with hereditary hemorrhagic telangiectasia. Am J Gastroenterol. 2003;98:59-65.

8. Health Service Circular, 2002/009. Better Blood Transfusion Appropriate Use of Blood. London, UK. Department of Health; 2002. Available from: http://www.dh.gov.uk/prod_consum_dh/groups/ dh_digitalassets/@dh/@en/documents/digitalasset/dh_4012293.pdf. Accessed November 8, 2011.

9. Health Service Circular, 2007/001. Better Blood Transfusion - Safe and Appropriate Use of Blood. London, UK. Department of Health; 2007. Available from: http://www.dh.gov.uk/prod_consum_dh/groups/ dh_digitalassets/documents/digitalasset/dh_080803.pdf. Accessed November 8, 2011.

10. MacDougall IC. Iron supplementation in the non-dialysis chronic kidney disease (ND-CKD) patient: oral or intravenous? Curr Med Res Opin. 2010;26:473-482.
11. Gasche C, Lomer MCE, Cavill, Weiss G. Iron, anemia, and inflammatory bowel disease. Gut. 2004;53:1190-1197.

12. Hallak M, Sharon AS, Diukman R, Auslender R, Abramovici H. Supplementing iron intravenously in pregnancy. A way to avoid blood transfusions. J Reprod Med. 1997;42:99-103.

13. Jenkins A. Using iron dextran to treat iron-deficiency anemia. Hospital Pharmacist. 2005;12:224-225.

14. Kim YH, Chung HH, Kang SB, Kim SC, Kim YT. Safety and usefulness of intravenous iron sucrose in the management of preoperative anemia in patients with menorrhagia: a phase IV, open label, prospective, randomized study. Acta Haematol. 2009;121:37-41.

15. Van Wyck DB, Mangione A, Morrison J, Hadley PE, Jehle JA, Goodnough LT. Large-dose intravenous ferric carboxymaltose injection for IDA in heavy uterine bleeding: a randomized, controlled trial. Transfusion. 2009;49:2719-2728.

16. Johnson DW, Herzig KA, Gissane R, et al. A prospective cross-over trial comparing intermittent intravenous and continuous oral iron supplementation in peritoneal dialysis patients. Nephrol Dial Transplant. 2001;16:1879-1884.

17. Melamed N, Ben-Haroush A, Kaplan B, Yogev Y. Iron supplementation in pregnancy - does the preparation matter? Arch Gynecol Obstet. 2007; 276:601-604.

18. CosmoFer. Summary of product characteristics. Oxford, UK: Pharmacosmos UK Ltd; 2011. Available from: http://www.medicines.org. uk/emc/medicine/14139/SPC/CosmoFer/. Accessed November 9, 2011.

19. Lebrin F, Srun S, Raymond K, et al. Thalidomide stimulates vessel maturation and reduces epistaxis in individuals with hereditary hemorrhagic telangiectasia. Nat Med. 2010;16:420-428.

20. World Health Organization. Nutritional Anaemias. Report of a WHO Scientific Group. Geneva, Switzerland: World Health Organization; 1968. Available from: http://whqlibdoc.who.int/trs/WHO_TRS_405. pdf. Accessed March 22, 2013.

21. World Health Organization. Serum ferritin concentrations for the assessment of iron status and iron deficiency in populations. Vitamin and Mineral Nutrition Information System. Geneva, Switzerland: World Health Organization; 2011. Available from: http://www.who.int/vmnis/ indicators/serum_ferritin.Pdf. Accessed May 9, 2012.

22. National Clinical Guideline Centre. Anaemia management in chronic kidney disease. London, UK: National Institute for Health and Clinical Excellence; 2011.

23. Besarab A, Kaiser JW, Frinak S. A study of parenteral iron regimens in hemodialysis patients. Am J Kidney Dis. 1999;34:21-28.

24. National Health Service Blood and Transplant Annual Review 2009/10. Saving and Improving Lives. Available from: http://www. organdonation.nhs.uk/ukt/newsroom/news_releases/printTemplate. jsp?rel. Accessed June 27, 2011.

25. British Thoracic Society. Handbook of Transfusion Medicine. UK Blood Transfusion and Tissue Transplantation Services. 4. Norwich, UK: The Stationery Office; 2007. Available from: http://www. transfusionguidelines.org/docs/pdfs/htm_edition-4_all-pages.pdf. Accessed November 9, 2011.

26. Auerbach M, Ballard H, Glaspy J. Clinical update: intravenous iron for anaemia. Lancet. 2007;369:1502-1604.
Drug, Healthcare and Patient Safety

\section{Publish your work in this journal}

Drug, Healthcare and Patient Safety is an international, peer-reviewed open-access journal exploring patient safety issues in the healthcare continuum from diagnostic and screening interventions through to treatment, drug therapy and surgery. The journal is characterized by the rapid reporting of reviews, original research, clinical, epidemiological and

\section{Dovepress}

post-marketing surveillance studies, risk management, health literacy and educational programs across all areas of healthcare delivery. The manuscript management system is completely online and includes a very quick and fair peer-review system. Visit http://www.dovepress.com/ testimonials.php to read real quotes from published authors. 